\title{
The role of internal jugular vein Doppler ultrasonography in predicting hypovolemic shock in polytrauma patients
}

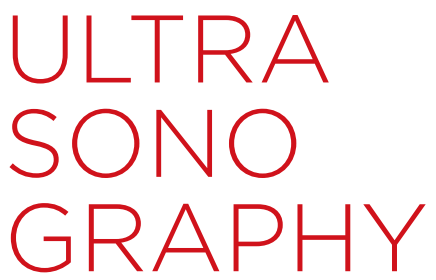

\author{
Hojatollah Khajehpour', Mohammad Javad Behzadnia² \\ 'Marine Medicine Research Center, Baqiyatallah University of Medical Sciences, Tehran; \\ ${ }^{2}$ Trauma Research Center, Baqiyatallah University of Medical Sciences, Tehran, Iran
}

\section{ORIGINAL ARTICLE}

https://doi.org/10.14366/usg.21144 pISSN: 2288-5919 - elSSN: 2288-5943 Ultrasonography 2022;41:317-324

Purpose: The aim of this study was to evaluate the accuracy of internal jugular vein (IJV) Doppler ultrasonography in predicting hypovolemic shock in polytrauma patients.

Methods: This prospective observational study was conducted on 75 multiple trauma patients (injury severity score $>15$ ) with a mean age of $33.00 \pm 9.57$ years. IJV Doppler ultrasonography was performed in all patients with stable vital signs and a negative extended focused assessment with sonography for trauma. Jugular pulsatility index (JPI) values were calculated using the equation $\left(V_{\max }-V_{\text {min }}\right) N_{\text {max }}$. Clinical and laboratory indices of hypovolemic shock were recorded at the time of admission. Patients were subsequently divided into those with hemorrhagic shock $(n=36)$ and those without $(n=39)$ based on the occurrence of hemorrhagic shock within 6 hours after admission. The results were compared between these groups.

Results: IJV Doppler ultrasound parameters (JPI, $\mathrm{V}_{\min }$ and $\mathrm{V}_{\max }-\mathrm{V}_{\min }$ ) showed significant differences between the two groups. The JPI values of patients with hemorrhagic shock were significantly lower than those in the control group $(0.43 \pm 0.21$ vs. $0.78 \pm 0.24, P<0.001)$. The sensitivity, specificity, and discriminant ability (area under the curve) of JPI with a cutoff of 0.58 in detecting hemorrhagic shock were $86.11 \%, 82.05 \%$, and $0.853(\mathrm{P}<0.001)$, respectively.

Conclusion: IJV Doppler ultrasonography can reliably predict hemorrhagic shock in polytrauma patients with stable vital signs. Ultrasonography can be used in combination with clinical signs and laboratory findings to diagnose patients at risk of hypovolemic shock.

Keywords: Doppler ultrasound; Hypovolemic shock; Internal jugular vein; Polytrauma patients Key points: Internal jugular vein Doppler ultrasonography is a non-invasive, accessible, highly sensitive, and specific method for diagnosing early hemorrhagic shock. The jugular pulsatility index would decline in early stage of hemorrhagic shock and could provide an accurate prediction of bleeding.

\section{Introduction}

Trauma is the leading cause of death in people under 45 years of age [1]. Traumatic hemorrhagic shock has a high incidence and is the cause of $80 \%$ of deaths among patients with survivable trauma

Received: July 4, 2021

Revised: August 28, 2021

Accepted: August 29, 2021

Correspondence to:

Hojatollah Khajehpour, MD, Marine Medicine Research Center, Baqiyatallah University of Medical Sciences, Nosrati Alley, Sheikh Bahaie St, Molla Sadra St, Vanaq sq., Tehran 1435915371, Iran

Tel. $+98-2181262012$

Fax. +98-2181262012

E-mail: hojatollah.khajehpour@yahoo. com

This is an Open Access article distributed under the terms of the Creative Commons Attribution NonCommercial License (http://creativecommons.org/ licenses/by-nc/4.0/) which permits unrestricted noncommercial use, distribution, and reproduction in any medium, provided the original work is properly cited.

Copyright (C) 2022 Korean Society of Ultrasound in Medicine (KSUM)

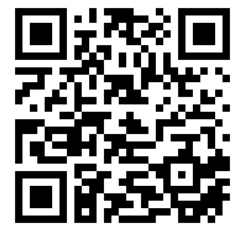

How to cite this article:

Khajehpour H, Behzadnia MJ. The role of internal jugular vein Doppler ultrasonography in predicting hypovolemic shock in polytrauma patients. Ultrasonography. 2022 Apr;41(2):317-324. 
$[1,2]$. Therefore, detecting hemorrhagic shock early is critical for effectively treating trauma patients and reducing the costs of care and patient deaths [1].

Several invasive and non-invasive methods have been proposed for measuring intravascular volume and fluid loss $[3,4]$. Various clinical examinations, including the systolic blood pressure (SBP), pulse rate (PR), and shock index (SI), all of which have variable sensitivities, have been used for these purposes [5]. Although laboratory methods, such as evaluating blood lactate levels and the blood base deficit, have good diagnostic accuracy, they are usually time-consuming and some of these methods lack reliability. Therefore, diagnosing a hypovolemic condition-especially in the early stages of hemorrhagic shock-and occult bleeding based on clinical examinations, vital signs, and laboratory tests can be challenging $[6,7]$.

Ultrasonography is a non-invasive, rapid, accessible, and usable clinical procedure that can be used to diagnose bleeding. Various ultrasound indices, including the inferior vena cava (IVC) diameter $[8,9]$, IVC collapsibility index [10], IVC to aortic diameter ratio [11], and jugular index [12], have been applied to evaluate fluid loss. These methods assess vein diameter, especially the diameter of the IVC. However, the results of these methods are contradictory $[9,13-15]$. Moreover, IVC ultrasonography can be difficult for most trauma patients due to the abdominal fat percentage, abdominal gas, and the long time it takes to measure this parameter. It is easier to assess the internal jugular vein (IJV) than the IVC. In this regard, respiratory changes in the IJV are helpful for evaluating intravascular fluid status $[7,16]$.

Intravascular volume loss is an inevitable consequence of bleeding. The two main parameters that affect volume loss are intravenous volume and cardiac output. These two parameters affect the flow pattern of IJV [17]. Thus, evaluating the flow pattern of the IJV by Doppler ultrasonography could provide more information on the patient's hemodynamics, blood loss, and response to venous resuscitation. The flow pattern of the IJV was recently proposed as a way to examine volume loss. A previous study examined IJV blood flow in blood donors after blood donation by Doppler ultrasonography and showed a decrease in the jugular pulsatility index (JPI) after blood donation. The JPI was calculated using the following equation: $\left(V_{\max }-V_{\min }\right) / V_{\max }[18]$.

To the best of our knowledge, IJV Doppler ultrasonography has not been examined yet in trauma patients. Given the high mortality risk of bleeding in trauma patients and the significance of the rapid diagnosis of bleeding in these patients, the present study was conducted to examine the relationship between IJV Doppler findings and hypovolemic shock in trauma patients.

\section{Materials and Methods}

\section{Compliance with Ethical Standards}

The study was conducted after obtaining permission from the Research Council and approval of from the Ethics Committee of the Baqiyatallah University of Medical Sciences (IR.BMSU. REC.1398.300). Informed written consent was received from all the patients or legal guardians. Moreover, in all stages of the study, the provisions of the ethics statement in the Helsinki study and the principles of patient information confidentiality were observed.

\section{Patients}

This prospective observational was conducted between January 1 , 2020, and December 30, 2020, on polytrauma patients admitted to Baqiyatallah al-Azam Hospital, Tehran, Iran.

The sample size was determined based on previous studies [18]. Using logistic regression analysis and values of $a=0.05$ and $\beta$ $=0.2$, a sample of at least 30 people in each group was calculated. Purposive sampling was conducted. The sample comprised polytrauma patients (injury severity score [ISS]>15) aged 18-60 years old. All participants had been transferred to the hospital within one and a half hours after suffering the trauma, and none showed any symptoms of hemorrhagic shock at the time of admission. Hemorrhagic shock was defined as any of the following: SBP less than $90 \mathrm{mmHg}$, decreased urinary output to $30 \mathrm{~mL} / \mathrm{h}$, blood loss more than $750 \mathrm{~mL}$, heart rate above $100 / \mathrm{min}$ or transfusion of $>2$ units of packed red blood cells (PRBCs) [19]. Moreover, patients with any of the following conditions were excluded from the study: pregnant patients; those with a direct penetrating or blunt injury to the right side of the neck (spine injury), known cardiac disease, pericardial effusion, pneumothorax, emergency thoracotomy, mechanical ventilation, flail chest, positive extended focused assessment with sonography for trauma (EFAST) results, hemoglobin ( $\mathrm{Hb}$ ) below 10 $\mathrm{mg} / \mathrm{dL}$, penetrating abdominal injury; and those who were taking vasoactive medicines.

\section{Patient Evaluation}

Upon admission, all patients were examined by an emergency physician and treated according to the Advanced Trauma Life Support guidelines. All vital signs were recorded, blood samples were taken for routine analysis, blood grouping and cross-matching were performed, and patients' demographic information was recorded. The laboratory parameters studied were blood lactate level, bicarbonate level $\left(\mathrm{HCO}_{3}\right)$, base excess $(\mathrm{BE})$, blood $\mathrm{pH}$, and $\mathrm{Hb}$. Additionally, patients' age, sex, injury mechanism, injury severity (based on ISS), the time elapsed between trauma and admission, and hospitalization duration before undergoing ultrasonography 
were examined and recorded. Patients' loss of consciousness was evaluated using the Glasgow Coma Scale (GCS). An experienced radiologist (with more than 10 years of experience) performed IJV ultrasonography in all patients. Ultimately, the patients were divided into two groups: those who experienced hemorrhagic shock during the first 6 hours and those who did not. Finally, the data obtained from both groups were compared.

\section{Ultrasound Evaluations}

EFAST was conducted on all patients no more than 10 minutes after admission to the emergency room. In the absence of free fluid in the abdomen and pelvis, right IJV Doppler ultrasonography was conducted as well. Patients who were EFAST-positive were excluded from the study.

For Doppler ultrasonography, patients were placed in the supine position, and the IJV was identified in the axial plane using a linear probe. Measurements were taken using a 5 to $12-\mathrm{MHz}$ linear probe of a Samsung HM70A ultrasound device (Samsung healthcare, Seoul, Korea). The probe was placed along the longitudinal plane, and the sample volume was determined to be one-third of the vein diameter, with an angle of insonation of $60^{\circ}$ or less. After three similar cycles were recorded, the maximum and minimum flow velocities $\left(V_{\max }\right.$ and $\left.V_{\text {min }}\right)$ of the IJV were determined (Fig. 1). Then, $V_{\text {max }}-V_{\text {min }}$ and the $V_{\text {max }} / V_{\text {min }}$ ratio were calculated. Finally, the JPI was calculated as $\left(\mathrm{V}_{\text {max }}-\mathrm{V}_{\text {min }}\right) / \mathrm{V}_{\text {max }}$.

\section{Statistical Analysis}

Statistical analyses were performed using SPSS for Windows version 22 (IBM Corp., Armonk, NY, USA) and MedCalc for Windows version 13 (MedCalc Software Ltd., Ostend, Belgium). The data were described in terms of mean, standard deviation, frequency,

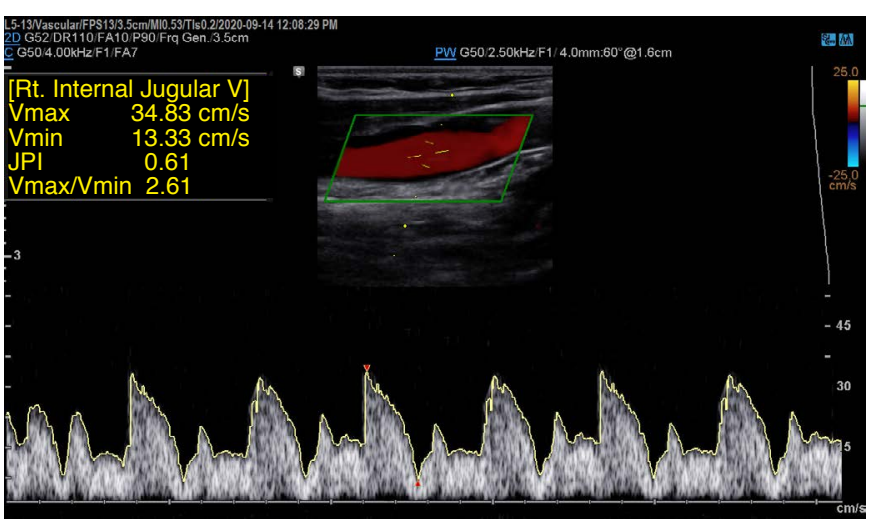

Fig. 1. Doppler ultrasound image showing the internal jugular vein (IJV). After three similar cycles were recorded, the maximum and minimum flow velocities $\left(V_{\max }\right.$ and $\left.V_{\min }\right)$ of the IJV were determined and the jugular pulsatility index (JPI) was calculated. and percentage. The normality of the data was examined using the Kolmogorov-Smirnov test. The Student t-test, chi-square test, and Pearson correlation coefficients were used to measure the differences and compare the variables. Various parameters of the receiver operating characteristic curve were evaluated, and the areas under the curve (AUCS) were compared to evaluate the diagnostic performance. The significance level of the tests was considered 0.05 . The sensitivity, specificity, positive predictive value (PPV), negative predictive value (NPV), positive likelihood ratio $(+L R)$, and negative likelihood ratio $(-L R)$ of each of the parameters for the diagnosis of hemorrhagic shock were reported.

\section{Results}

Out of 350 hospitalized polytrauma patients, 275 were excluded and 75 patients aged 19 to 57 years participated in this study. The flowchart of the study is presented in Fig. 2.

The basic characteristics of the patients from both groups are presented in Table 1. There were no significant differences between patients with and without hemorrhagic shock in terms of age, sex, mechanism of trauma, the time between trauma and hospitalization, and the time between admission to the emergency ward and undergoing ultrasonography $(\mathrm{P}>0.05)$.

Table 2 shows the results of vital signs, clinical parameters, and ultrasonography. The two groups did not differ significantly in terms of $S B P$, respiratory rate (RR), $p H, G C S, P R$, or $H b(P>0.05)$. Significant

Table 1. Comparison of the basic characteristics of patients with or without hemorrhagic shock

\begin{tabular}{|c|c|c|c|}
\hline Characteristic & $\begin{array}{l}\text { Hemorrhagic } \\
\text { shock group } \\
\quad(n=36)\end{array}$ & $\begin{array}{c}\text { No hemorrhagic } \\
\text { shock group } \\
(n=39)\end{array}$ & P-value \\
\hline Age (year) & $33.47 \pm 9.27$ & $32.56 \pm 9.93$ & 0.684 \\
\hline \multicolumn{4}{|l|}{ Sex } \\
\hline Male & $26(72.2)$ & $28(71.8)$ & 0.967 \\
\hline Female & $10(27.8)$ & $11(28.2)$ & \\
\hline \multicolumn{4}{|l|}{ Trauma mechanism } \\
\hline Fall & $3(8.3)$ & $5(12.8)$ & 0.475 \\
\hline Motor vehicle collision & $27(75.0)$ & $29(74.4)$ & \\
\hline $\begin{array}{l}\text { Motorcycle or pedestrian } \\
\text { accident with car }\end{array}$ & $6(16.7)$ & $5(12.8)$ & \\
\hline $\begin{array}{l}\text { The time elapsed between } \\
\text { trauma and admission (min) }\end{array}$ & $36.94 \pm 14.01$ & $38.56 \pm 12.42$ & 0.597 \\
\hline $\begin{array}{l}\text { Hospitalization duration before } \\
\text { undergoing ultrasonography } \\
\text { (min) }\end{array}$ & $11.44 \pm 3.38$ & $10.13 \pm 3.90$ & 0.125 \\
\hline
\end{tabular}

Values are presented as mean \pm standard deviation or number (\%). $\mathrm{P}<0.05$ was considered to indicate statistical significance. 


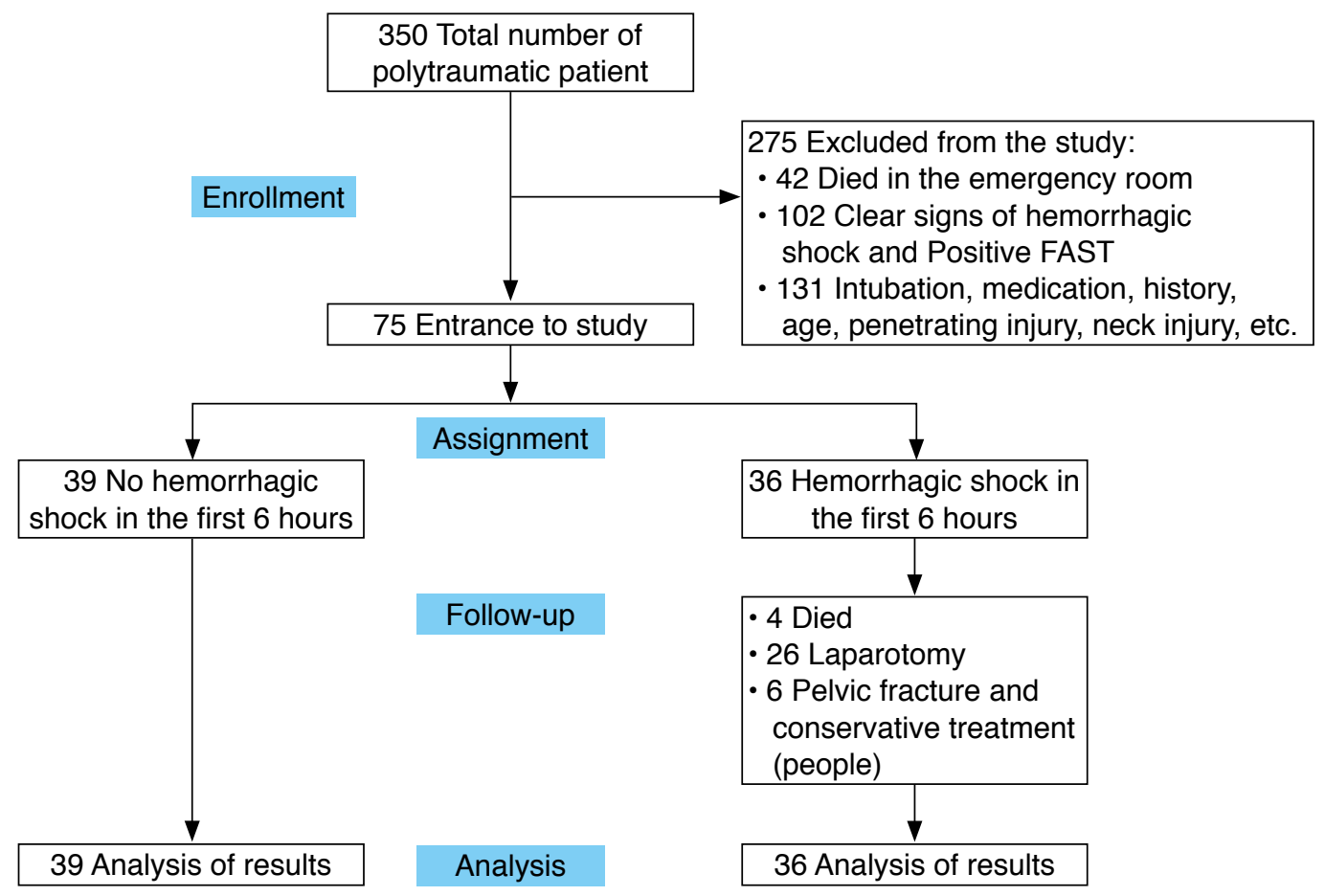

Fig. 2. Study flow diagram. FAST, focused assessment with sonography for trauma.

Table 2. Comparison of the vital signs, clinical parameters, and ultrasound findings of the patients examined

\begin{tabular}{|c|c|c|c|}
\hline Variable & Hemorrhagic shock group $(n=36)$ & No hemorrhagic shock group $(n=39)$ & P-value \\
\hline $\mathrm{SBP}(\mathrm{mmHg})$ & $116.64 \pm 10.79$ & $119.51 \pm 7.71$ & 0.186 \\
\hline $\mathrm{PR}(\mathrm{bpm})$ & $91.92 \pm 11.19$ & $89.41 \pm 9.07$ & 0.289 \\
\hline $\mathrm{SI}$ & $0.78 \pm 0.09$ & $0.73 \pm 0.06$ & 0.016 \\
\hline RR & $19.86 \pm 6.36$ & $17.69 \pm 5.98$ & 0.133 \\
\hline GCS & $13.94 \pm 0.98$ & $14.33 \pm 0.70$ & 0.051 \\
\hline ISS & $29.64 \pm 5.18$ & $26.56 \pm 6.71$ & 0.031 \\
\hline Standard base excess (mEq/L) & $-4.62 \pm 3.45$ & $1.10 \pm 2.01$ & $<0.001$ \\
\hline $\mathrm{HCO}_{3}(\mathrm{mmol} / \mathrm{L})$ & $20.05 \pm 4.43$ & $23.7 \pm 3.23$ & $<0.001$ \\
\hline $\mathrm{pH}$ & $7.35 \pm 0.34$ & $7.37 \pm 0.45$ & 0.154 \\
\hline Lactate (mmol/L) & $2.83 \pm 0.84$ & $2.09 \pm 1.03$ & 0.001 \\
\hline Hemoglobin (g/dL) & $12.48 \pm 1.17$ & $13.08 \pm 1.48$ & 0.058 \\
\hline PRBCs in first $6 \mathrm{~h}$ (unit) & $4.08 \pm 3.18$ & $0.61 \pm 0.84$ & $<0.001$ \\
\hline$V_{\max }(\mathrm{cm} / \mathrm{s})$ & $49.04 \pm 15.91$ & $52.83 \pm 16.12$ & 0.309 \\
\hline$V_{\min }(\mathrm{cm} / \mathrm{s})$ & $25.52 \pm 11.87$ & $17.01 \pm 15.55$ & 0.010 \\
\hline$V_{\max }-V_{\min }(\mathrm{cm} / \mathrm{s})$ & $24.14 \pm 16.52$ & $35.00 \pm 19.93$ & 0.013 \\
\hline $\mathrm{V}_{\max } / \mathrm{N}_{\min }$ & $2.73 \pm 2.78$ & $3.80 \pm 2.21$ & 0.067 \\
\hline$J P \mid$ & $0.43 \pm 0.21$ & $0.78 \pm 0.24$ & $<0.001$ \\
\hline
\end{tabular}

Values are presented as mean \pm standard deviation.

SBP, systolic blood pressure; PR, pulse rate; SI, shock index; RR, respiratory rate; GCS, Glasgow Coma Scale; ISS, injury severity score; $\mathrm{HCO}_{3}$, bicarbonate level; PRBCs, packed red blood cells; $V_{\max }$ maximum velocity; $V_{\min ,}$ minimum velocity; JPI, jugular pulsatility index.

differences between the two groups were detected for other clinical parameters (SI and ISS), laboratory parameters (lactate level, $\mathrm{HCO}_{3}$, and $\mathrm{BE})$, and ultrasound parameters $\left(\mathrm{V}_{\min ,} \mathrm{V}_{\max }-\mathrm{V}_{\min }\right.$ and JPI).
The relationships of the JPI with various parameters in the patients in the two groups are presented in Table 3. Significant relationships were observed between the JPI and transfused PRBCs, BE, $\mathrm{HCO}_{3}$, 
lactate, ISS, SI, and GCS in patients with hemorrhagic shock. There were no significant relationships for other variables. Significant relationships were found between the JPI and transfused PRBCs, BE, $\mathrm{HCO}_{3}$, lactate, ISS, and $\mathrm{SI}$ in the patients without hemorrhagic shock.

Table 4 presents the sensitivity, specificity, $+L R$, $-L R, P P V, N P V$, and $A U C$ for each parameter that had significant differences between the two groups and was examined for the diagnosis of hemorrhagic shock. The best discriminant ability was shown by BE (AUC, 0.925), JPI (AUC, 0.853), $\mathrm{HCO}_{3}$ (AUC, 0.851), and ISS (AUC, $0.832)(P<0.001)$. Fig. 3 shows the comparison of the discriminant ability of various parameters based on the AUC.

\section{Discussion}

Conventional methods for quickly diagnosing bleeding in trauma patients are not reliable [5]. Rouhezamin et al. [18] showed that clinical indicators such as PR, SBP, and SI could not predict the early stages of hypovolemic shock in blood donors. Other studies have reported that clinical data and vital signs are unreliable indices for detecting the early stages of hemorrhagic shock $[20,21]$. The present study findings confirm those findings; specifically, there were no significant differences in $\mathrm{SBP}, \mathrm{RR}, \mathrm{pH}, \mathrm{PR}$, and $\mathrm{Hb}$ between patients with and without hemorrhagic shock, suggesting that these parameters do not reliably predict bleeding. Among laboratory tests, an increased base deficit indicates lactic acidosis and anaerobic metabolism due to impaired tissue perfusion. Previous studies have indicated that venous blood gases and lactate levels accurately predict volume loss and hypovolemic shock, but some of these indices are not accurate enough to detect small volumes of blood loss and are unavailable at the patient's bedside [18,22-24]. In the present study, an increased base deficit was the best indicator of hemorrhagic shock; however, although this index is an acceptable

Table 3. Relationships between the jugular pulsatility index and various parameters in the patients who were examined

\begin{tabular}{|c|c|c|c|c|}
\hline \multirow{2}{*}{ Variable } & \multicolumn{2}{|c|}{ Hemorrhagic shock group $(n=36)$} & \multicolumn{2}{|c|}{ No hemorrhagic shock group $(n=39)$} \\
\hline & Pearson correlation & P-value & Pearson correlation & P-value \\
\hline$P R$ & -0.148 & 0.388 & 0.081 & 0.623 \\
\hline SBP & -0.204 & 0.233 & -0.219 & 0.180 \\
\hline SI & $-0.459^{* *}$ & 0.005 & $-0.456^{* *}$ & 0.004 \\
\hline RR & -0.049 & 0.775 & 0.188 & 0.475 \\
\hline GCS & $0.366^{*}$ & 0.028 & 0.038 & 0.818 \\
\hline ISS & $-0.502^{* *}$ & 0.002 & $-0.353^{*}$ & 0.028 \\
\hline Base excess & $0.398^{*}$ & 0.016 & $0.463^{* *}$ & 0.003 \\
\hline $\mathrm{HCO}_{3}$ & $0.532^{* *}$ & 0.001 & $0.319^{*}$ & 0.047 \\
\hline $\mathrm{pH}$ & 0.318 & 0.058 & 0.008 & 0.963 \\
\hline Lactate & $-0.417^{*}$ & 0.011 & $-0.397^{*}$ & 0.012 \\
\hline $\mathrm{Hb}$ & 0.006 & 0.971 & 0.093 & 0.574 \\
\hline PRBCs & $-0.751^{* *}$ & $<0.001$ & $-0.803^{* *}$ & $<0.001$ \\
\hline
\end{tabular}

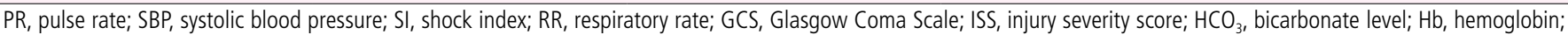
PRBCs, packed red blood cells.

${ }^{*}$ Significant relationship at $\mathrm{P}<0.05$. * ${ }^{*}$ Significant relationship at $\mathrm{P}<0.01$.

Table 4. The accuracy of various parameters in the diagnosis of hemorrhagic shock

\begin{tabular}{lcccccccccc}
\hline \multicolumn{1}{c}{ Variable } & Cutoff & Sensitivity & Specificity & + LR & - LR & PPV & NPV & AUC & $95 \% \mathrm{Cl}$ & P-value \\
\hline $\mathrm{SI}$ & $>0.82$ & 38.89 & 94.87 & 7.58 & 0.64 & 87.5 & 62.7 & 0.636 & $0.516-0.744$ & 0.040 \\
ISS & $>32$ & 69.44 & 97.44 & 27.08 & 0.31 & 96.2 & 77.6 & 0.832 & $0.728-0.909$ & $<0.001$ \\
Base excess $(\mathrm{mEq} / \mathrm{L})$ & $\leq-2.1$ & 80.56 & 92.31 & 10.47 & 0.21 & 90.6 & 83.7 & 0.925 & $0.840-0.973$ & $<0.001$ \\
Lactate $(\mathrm{mmol} / \mathrm{L})$ & $>1.9$ & 86.11 & 46.15 & 1.60 & 0.30 & 59.6 & 78.3 & 0.702 & $0.585-0.802$ & $<0.001$ \\
$\mathrm{~V}_{\min }(\mathrm{cm} / \mathrm{s})$ & $>14.61$ & 83.33 & 61.54 & 2.17 & 0.27 & 66.7 & 80 & 0.693 & $0.576-0.795$ & 0.003 \\
$\mathrm{JPI}$ & $\leq 0.58$ & 86.11 & 82.05 & 4.80 & 0.17 & 81.6 & 86.5 & 0.853 & $0.752-0.924$ & $<0.001$ \\
$\mathrm{HCO}_{3}(\mathrm{mmol} / \mathrm{L})$ & $\leq 21.2$ & 72.22 & 92.31 & 9.39 & 0.30 & 89.7 & 78.3 & 0.851 & $0.751-0.923$ & $<0.001$ \\
\hline
\end{tabular}

LR, likelihood ratio; PPV, positive predictive value; NPV, negative predictive value; AUC, area under the curve; Cl, confidence interval; SI, shock index; ISS, injury severity score; $\mathrm{V}_{\min }$ minimum velocity; JPI, jugular pulsatility index; $\mathrm{HCO}_{3}$, bicarbonate level. 


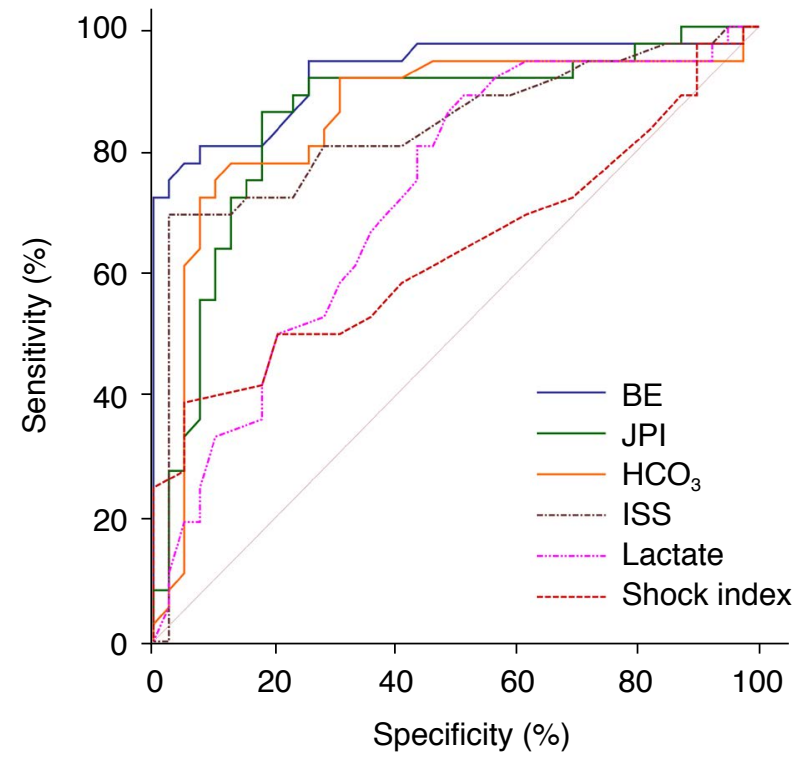

Fig. 3. Comparison of the discriminant ability of different parameters for hemorrhagic shock. According to the area under the curve, the best discriminant ability was shown by base excess (BE), jugular pulsatility index (JPI), bicarbonate level $\left(\mathrm{HCO}_{3}\right)$, and injury severity score (ISS).

prognostic factor in trauma patients, other factors (e.g., hypocapnia, hyponatremia, and acidosis) can affect it [25].

Ultrasonography is an alternative tool for the diagnosis of volume loss. Celik et al. [14] found no significant associations between the IVC diameter or aorta diameter in trauma patients and clinical signs or laboratory tests. Furthermore, Juhl-Olsen et al. [9] assessed blood donors and detected no significant relationships between the IVC diameter (measured using ultrasonography) and cardiac output or the hemodynamic response in the early hemorrhagic stages.

Pucheu was the first researcher to explain that the typical Doppler flow pattern of the IJV is pulsatile [26]. Cardiac output and intravascular volume affect the venous dynamics and waveform [17]. Blood loss also affects these factors. Reduced cardiac output and venous return were reported in cases of bleeding and volume loss even without clinical signs of shock. However, other compensatory mechanisms maintain the oxygenation of vital organs such as the brain [27]. As a result, blood flow to the brain increases, while absolute cerebral blood flow and cerebral venous flow are slightly reduced [28]. At the same time, absolute and relative extracranial peripheral blood flow (facial muscles) also decreases [29]. In other words, absolute IJV blood flow decreases after volume loss [18], thus reducing the difference between the maximum and minimum flow $\left(V_{\text {max }}-V_{\text {min }}\right)$ as the pulsatility of the IJV (JPI) decreases.

In a comparison of blood donors and control participants, Rouhezamin et al. [18] showed that the JPI declined significantly after blood donation and provided an accurate prediction of bleeding (AUC, 0.711). Moreover, they showed that using this index simultaneously with clinical and laboratory parameters (SI and base deficit) could improve the discriminant ability (AUC, 0.868).

In the present study, patients with hemorrhagic shock and without hemorrhagic shock exhibited significantly different flow pattern parameters in IJV ultrasonography (including $\mathrm{V}_{\text {min, }} \mathrm{V}_{\text {max }}-\mathrm{V}_{\text {min, }}$ and the JPI). The JPI of the patients with hemorrhagic shock was significantly lower than that of the patients without hemorrhagic shock. The JPI also had good discriminant ability, with high sensitivity and specificity for predicting the occurrence of hemorrhagic shock (AUC, 0.853).

The significant relationships between JPI and $\mathrm{HCO}_{3}, \mathrm{BE}$, and lactate are reasonable, as previous studies have indicated the high diagnostic performance of these parameters. The JPI also showed a significant relationship with PRBCs transfused in the first 6 hours.

Overall, the results show that ultrasound parameters (JPI in the present study and IVC diameter in other studies $[9,14]$ ) are not associated with hemodynamic parameters. This is reasonable, as clinical and laboratory parameters do not accurately predict the early stage of hemorrhagic shock, and these parameters have shown variable sensitivity in previous studies $[5,6]$.

Ultimately, the findings of the present study indicate that the IJV Doppler flow pattern evaluation has acceptable sensitivity and specificity for diagnosing hemorrhagic shock in trauma patients. Ultrasound devices are now available in all emergency departments and are easy to use. Therefore, IJV Doppler ultrasonography can be used with other clinical signs and blood gas parameter assessments as a supplement to the focused assessment with sonography for trauma examination.

The present study is the first to evaluate the function of IJV Doppler ultrasonography in diagnosing hypovolemic shock in polytrauma patients. Previous studies have focused on using IJV ultrasonography to assess hypovolemic shock after blood donation, with a focus on the diameter of the IJV $[7,12,15,18]$. Although blood donation can be used as a hemorrhagic shock model because the intravascular volume decreases rapidly after blood donation, vital signs change little during this process [30].

The present study has some limitations. For example, the relatively small sample that comprised only young and middle-aged patients could have influenced the results. However, the statistical analysis was not affected by this limitation. More accurate results might be obtained by carrying out more studies with larger samples.

IJV Doppler evaluations accurately predicted hemorrhagic shock in patients with polytrauma. IJV Doppler ultrasonography is a non-invasive, accessible, highly sensitive, and specific method for diagnosing early hemorrhagic shock. It can be routinely used in 
clinical examinations to identify patients at risk for hypovolemic shock.

ORCID: Hojatollah Khajehpour: https://orcid.org/0000-0002-2999-4550; Mohammad Javad Behzadnia: https://orcid.org/0000-0002-3062-0839

\section{Author Contributions}

Conceptualization: Khajehpour H, Behzadnia MJ. Data acquisition: Khajehpour H, Behzadnia MJ. Data analysis or interpretation: Khajehpour H, Behzadnia MJ. Drafting of the manuscript: Khajehpour $\mathrm{H}$, Behzadnia MJ. Critical revision of the manuscript: Behzadnia MJ. Approval of the final version of the manuscript: all authors.

\section{Conflict of Interest}

No potential conflict of interest relevant to this article was reported.

\section{Acknowledgments}

This study (with registered number 98000154) was conducted jointly between the Clinical Research Development Unit of Baqiyatallah Hospital and the Marine Medicine Research Center of Baqiyatallah University of Medical Sciences in collaboration with Dr. Sahraei from the Supreme National Defense University.

\section{References}

1. Eastridge BJ, Holcomb JB, Shackelford S. Outcomes of traumatic hemorrhagic shock and the epidemiology of preventable death from injury. Transfusion 2019;59:1423-1428.

2. Teixeira PG, Inaba K, Hadjizacharia P, Brown C, Salim A, Rhee P, et al. Preventable or potentially preventable mortality at a mature trauma center. J Trauma 2007;63:1338-1346.

3. Sakka SG. Hemodynamic monitoring in the critically ill patient: current status and perspective. Front Med (Lausanne) 2015;2:44.

4. Monnet X, Dres M, Ferre A, Le Teuff $G$, Jozwiak M, Bleibtreu A, et al. Prediction of fluid responsiveness by a continuous non-invasive assessment of arterial pressure in critically ill patients: comparison with four other dynamic indices. Br J Anaesth 2012;109:330-338.

5. Witting MD. Standing shock index: an alternative to orthostatic vital signs. Am J Emerg Med 2017;35:637-639.

6. Caputo ND, Kanter M, Fraser R, Simon R. Comparing biomarkers of traumatic shock: the utility of anion gap, base excess, and serum lactate in the ED. Am J Emerg Med 2015;33:1134-1139.

7. Tokunaga K, Nakamura K, Inokuchi R, Hayase N, Terada R, Tomioka $\mathrm{Y}$, et al. Cardiac variation of internal jugular vein as a marker of volume change in hemorrhagic shock. Shock 2020;54:717-722.

8. Schefold JC, Storm C, Bercker S, Pschowski R, Oppert M, Kruger $A$, et al. Inferior vena cava diameter correlates with invasive hemodynamic measures in mechanically ventilated intensive care unit patients with sepsis. J Emerg Med 2010;38:632-637.

9. Juhl-Olsen P, Vistisen ST, Christiansen LK, Rasmussen LA, Frederiksen $C A$, Sloth $E$. Ultrasound of the inferior vena cava does not predict hemodynamic response to early hemorrhage. J Emerg Med 2013;45:592-597.

10. Sefidbakht $S$, Assadsangabi R, Abbasi HR, Nabavizadeh A. Sonographic measurement of the inferior vena cava as a predictor of shock in trauma patients. Emerg Radiol 2007;14:181-185.

11. Rahman NH, Ahmad R, Kareem MM, Mohammed MI. Ultrasonographic assessment of inferior vena cava/abdominal aorta diameter index: a new approach of assessing hypovolemic shock class 1. Int J Emerg Med 2016;9:8.

12. Akilli NB, Cander B, Dundar ZD, Koylu R. A new parameter for the diagnosis of hemorrhagic shock: jugular index. J Crit Care 2012;27:530.

13. Worapratya P, Anupat S, Suwannanon R, Wuthisuthimethawee P. Correlation of caval index, inferior vena cava diameter, and central venous pressure in shock patients in the emergency room. Open Access Emerg Med 2014;6:57-62.

14. Celik OF, Akoglu H, Celik A, Asadov R, Onur OE, Denizbasi A. Initial inferior vena cava and aorta diameter parameters measured by ultrasonography or computed tomography does not correlate with vital signs, hemorrhage or shock markers in trauma patients. Ulus Travma Acil Cerrahi Derg 2018;24:351-358.

15. Unluer $\mathrm{EE}$, Kara $\mathrm{PH}$. Ultrasonography of jugular vein as a marker of hypovolemia in healthy volunteers. Am J Emerg Med 2013;31:173177.

16. Lipton B. Estimation of central venous pressure by ultrasound of the internal jugular vein. Am J Emerg Med 2000;18:432-434.

17. Zhang Y, Chu JC, Hsi W, Khan AJ, Mehta PS, Bernard DB, et al. Evaluation of four volume-based image registration algorithms. Med Dosim 2009;34:317-322.

18. Rouhezamin MR, Shekarchi B, Taheri Akerdi A, Paydar S. Internal jugular vein waveform: a new insight to detect early stage of hemorrhagic shock. Bull Emerg Trauma 2019;7:263-268.

19. Mutschler M, Nienaber U, Brockamp T, Wafaisade A, Wyen H, Peiniger $S$, et al. A critical reappraisal of the ATLS classification of hypovolaemic shock: does it really reflect clinical reality? Resuscitation 2013;84:309-313.

20. Brasel KJ, Guse C, Gentilello LM, Nirula R. Heart rate: is it truly a vital sign? J Trauma 2007;62:812-817.

21. Pacagnella RC, Souza JP, Durocher J, Perel P, Blum J, Winikoff B, et al. A systematic review of the relationship between blood loss and clinical signs. PLoS One 2013;8:e57594.

22. Dunham MP, Sartorius B, Laing GL, Bruce JL, Clarke DL. A comparison of base deficit and vital signs in the early assessment of patients with penetrating trauma in a high burden setting. Injury 2017;48:1972-1977. 
23. Sinert R, Zehtabchi S, Bloem C, Lucchesi M. Effect of normal saline infusion on the diagnostic utility of base deficit in identifying major injury in trauma patients. Acad Emerg Med 2006;13:1269-1274.

24. Mutschler M, Nienaber U, Brockamp T, Wafaisade A, Fabian $T$, Paffrath $T$, et al. Renaissance of base deficit for the initial assessment of trauma patients: a base deficit-based classification for hypovolemic shock developed on data from 16,305 patients derived from the TraumaRegister DGU(R). Crit Care 2013;17:R42.

25. Maar SP. Searching for the Holy Grail: a review of markers of tissue perfusion in pediatric critical care. Pediatr Emerg Care 2008;24:883-887.

26. Pucheu A, Evans J, Thomas D, Scheuble C, Pucheu M. Doppler ultrasonography of normal neck veins. J Clin Ultrasound
1994;22:367-373.

27. Carter EA, Tompkins RG, Yarmush ML, Walker WA, Burke JF. Redistribution of blood flow after thermal injury and hemorrhagic shock. J Appl Physiol (1985) 1988;65:1782-1788.

28. Sun N, Li LZ, Luo W, Luo Q. Cerebral hemodynamic change and metabolic alteration in severe hemorrhagic shock. Adv Exp Med Biol 2014;812:217-223.

29. Dutton RP. Low-pressure resuscitation from hemorrhagic shock. Int Anesthesiol Clin 2002;40:19-30.

30. World Health Organization. Guidelines on assessing donor suitability for blood donation. Geneva: World Health Organization, 2018. 